\title{
Cross sectional echocardiographic assessment of the aortic root and coronary ostial stenosis in familial hypercholesterolaemia
}

\author{
P RIBEIRO, L M SHAPIRO, A GONZALEZ, G R THOMPSON, CELIA M OAKLEY \\ From the Department of Clinical Cardiology, Royal Postgraduate Medical School, and MRC Lipid Metabolism \\ Unit, Hammersmith Hospital, London
}

SUMMARY Aortic root abnormalities (atherosclerotic thickening and obstruction) seen at necropsy may readily be detected by aortography in familial hypercholesterolaemia. We studied 35 patients with familial types IIa and IIb hyperlipoproteinaemia including three homozygotes and 32 heterozygotes. Two homozygotes showed abnormal bright echoes (atheroma) encircling the proximal aortic root, which interfered with full excursion of the aortic cusps. One homozygote showed the typical echocardiographic features of supravalvular aortic stenosis at the superior border of the sinus of Valsava with normal aortic cusps. Cardiac catheterisation showed valvular gradients of 15 and 80 $\mathrm{mm} \mathrm{Hg}$ in two homozygotes and a supravalvular gradient of $40 \mathrm{~mm} \mathrm{Hg}$ in the third. Left coronary artery ostial stenosis was identified by echocardiography in all three homozygotes. Echocardiographic measurements of the aortic root in the 32 heterozygotes were similar to the control group, but 10 patients showed abnormal bright echoes within the aortic cusps and four had supravalvular changes similar to, but less severe than, the homozygotes. In one severely heterozygote supravalvular atheroma prevented full aortic cusp excursion, and this finding was confirmed during coronary artery bypass surgery.

Patients with homozygous familial hypercholesterolaemia have a high mortality due to premature atheroma, ${ }^{1}$ which predominantly affects the proximal coronary arteries and aortic root. ${ }^{2}$

The aortic valve and root in homozygotes are thickened and infiltrated by atheroma. Histologically, these lesions consist of atheroma with a large number of foam cells, and they have a high cholesterol content. ${ }^{2}$ The deposition of intracellular lipid and the finding of cholesterol crystals within the aortic valve is pathognomonic for this condition and can lead to severe aortic stenosis. ${ }^{34}$ Aortography shows characteristic aortic root funnelling. ${ }^{5}$ Involvement of the aortic valve is considered a unique feature of the homozygote. ${ }^{6}$ An aortic systolic murmur has, however, been reported in $30 \%$ of heterozygotes. ${ }^{7}$ Pathological studies in heterozygotes showed frequent supravalvular atheroma deposition, but aortic valve involvement was found in only one of 11 patients. ${ }^{2}$

The purpose of this study was to assess the use of

Accepted for publication 26 July 1983 cross sectional echocardiography for identifying aortic root lesions and coronary artery ostial stenosis in homozygotes and to determine whether similar abnormalities were present in heterozygotes.

\section{Patients}

Thirty five patients with familial hypercholesterolaemia attending the Hammersmith Hospital lipid clinic were studied, of whom three were homozygotes and 32 were heterozygotes.

\section{HOMOZYGOTES}

Three males (aged 14, 19, and 25 years), who were all receptor defective and who have been previously described in detail ${ }^{5}$ had pretreatment serum cholesterol concentrations of 16,18 , and $22 \mathrm{mmol} / \mathrm{l}(618$, 695 , and $849 \mathrm{mg} / 100 \mathrm{ml}$ ) respectively. All were undergoing plasma exchange at two-weekly intervals.

\section{HETEROZYGOTES}

Thirty two patients (22 males, 10 females), with a 
mean age of $42.7 \pm 11.7$ years had pretreatment serum cholesterol concentrations (mean $\pm S D$ ) of $8.8 \pm 2.0$ $\mathrm{mmol} / \mathrm{l}(340 \pm 77 \mathrm{mg} / 100 \mathrm{ml})$. The diagnosis of familial hypercholesterolaemia was based on serum cholesterol concentration $\geqslant 7.5 \mathrm{mmol} / \mathrm{l}(290 \mathrm{mg} / 100 \mathrm{ml})$ and the presence of tendon xanthomata or a history of hypercholesterolaemia with tendon xanthomata or premature myocardial infarction in a first degree relative. All heterozygotes were on a cholesterol lowering diet and many were also taking cholestyramine, nicotinic acid, or probucol.

\section{CONTROLS}

Thirty two age matched healthy normolipidaemic controls were included for comparision.

\section{Methods}

All patients underwent standard cross sectional echocardiographic study in the partial left lateral position with an ATL M1 mechanical sector scanner using parasternal and short axis views. Measurements of aortic root dimensions were made from sector guided $M$ mode traces at end diastole, and an average measurement from five consecutive cardiac cycles was obtained. Echocardiograms were inspected for aortic root or valve abnormalities, especially cusp or wall thickening. Two sets of echocardiographic measurements were made. (1) In the three homozygotes and in one heterozygote comparisons with standard cineaortographic measurements were made by measuring the diameter of the inner aspect of the aortic root at three levels: (a) aortic annulus; $(b)$ upper border of sinus of Valsalva; and $(c) 1.5 \mathrm{~cm}$ above $(b)$. (2) In all the remaining heterozygotes standard echocardiographic aortic root measurements were made in the long axis view both at the annulus and at the mid-level of the sinus of Valsalva. ${ }^{8}$

Three homozygotes and one heterozygote underwent contrast cineaortography, measurements (as described above) being made in the right anterior oblique and left lateral projections and corrected for magnification.

Angiographic and echocardiographic measurements were made by different observers. Values are quoted as mean $\pm 1 S D$, and the Mann Whitney $U$ test was used to test the differences between means.

\section{Results}

\section{HOMOZYGOTES}

Similar (within $0.3 \mathrm{~cm}$ ) echocardiographic and angiographic measurements of aortic root dimensions were obtained in all three subjects (Table). Abnormal bright echoes could be seen encircling the aortic root, especially within the sinus of Valsalva, suggesting generalised funnelling of the supravalvular aorta. One of the homozygotes (case 1) showed a considerable reduction (47\%) in the supravalvular aortic dimension at the superior border of the sinus of Valsalva when compared with the aortic diameter at the annulus without any limitation of the motion of the aortic valve cusps (Fig. 1); at cardiac catheterisation a supravalvular gradient of $40 \mathrm{~mm} \mathrm{Hg}$ was noted. The other homozygotes showed moderate supravalvular narrowing (32 and 23\%), but the site of haemodynamic obstruction was valvular (gradients of 15 and $80 \mathrm{~mm} \mathrm{Hg}$ ). In both cases a bright mass of echoes indicated atheroma in the sinus of Valsalva, which interfered with the opening of the right and non-coronary aortic valve cusps (Fig. 2). This finding was confirmed at cardiac surgery in one patient. The aortic cusps were thickened particularly in the basal portion, and both patients had a gradient at the valvular level. One homozygote also showed generalised mitral valve thickening (Fig. 2a). Serial parasternal short axis views showed extension of the abnormal aortic root with bright echoes extending into the origin of the left main coronary artery in all three homozygotes (Fig. 3).

\section{HETEROZYGOTES}

The main aortic root dimensions were $2.8 \pm 0.4 \mathrm{~cm}$ (annulus) and $3.1 \pm 0.5 \mathrm{~cm}$ (mid-sinus of Valsalva). These were similar to dimensions in normal controls $(3.0 \pm 0.4 \mathrm{~cm}$ and $3.3 \pm 0.3 \mathrm{~cm}$ respectively). Ten patients had abnormal bright echoes arising from the aortic valve; in six more than one cusp was affected. The non-coronary cusp was affected in eight, and right and left coronary cusps in seven and three

Table Echocardiographic and angiographic measurements of the aortic root diameter

\begin{tabular}{|c|c|c|c|c|c|c|c|}
\hline \multirow[t]{2}{*}{ Case No. } & \multicolumn{2}{|c|}{ Annulus } & \multicolumn{2}{|c|}{ Superior border of sinus of Valsalva } & \multicolumn{2}{|c|}{$1.5 \mathrm{~cm}$ above sinus of Valsalva } & \multirow[t]{2}{*}{ Aortic gradient ( $m m \mathrm{Hg}$ ) } \\
\hline & Echo & Angio & Echo & Angio & Echo & Angio & \\
\hline $\begin{array}{l}1 \text { Homozygote } \\
2 \text { Homozygote } \\
3 \text { Homozygote } \\
4 \text { Heterozygote }\end{array}$ & $\begin{array}{l}1.9 \\
2.2 \\
2.1 \\
1.8\end{array}$ & $\begin{array}{l}1 \cdot 8 \\
1.9 \\
2.1 \\
2.1\end{array}$ & $\begin{array}{l}1.0 \\
1.5 \\
1.7 \\
1.4\end{array}$ & $\begin{array}{l}1.0 \\
1.7 \\
1.5 \\
2.6\end{array}$ & $\begin{array}{l}2.6 \\
2.5 \\
2.5 \\
2.6\end{array}$ & $\begin{array}{l}2 \cdot 7 \\
2 \cdot 4 \\
2 \cdot 4 \\
2 \cdot 7\end{array}$ & $\begin{array}{l}40 \text { (supravalvular) } \\
80 \text { (valvular) } \\
15 \text { (valvular) } \\
15 \text { (valvular) }\end{array}$ \\
\hline
\end{tabular}

Echo, echocardiographic measurement; Angio, angiographic measurement. 

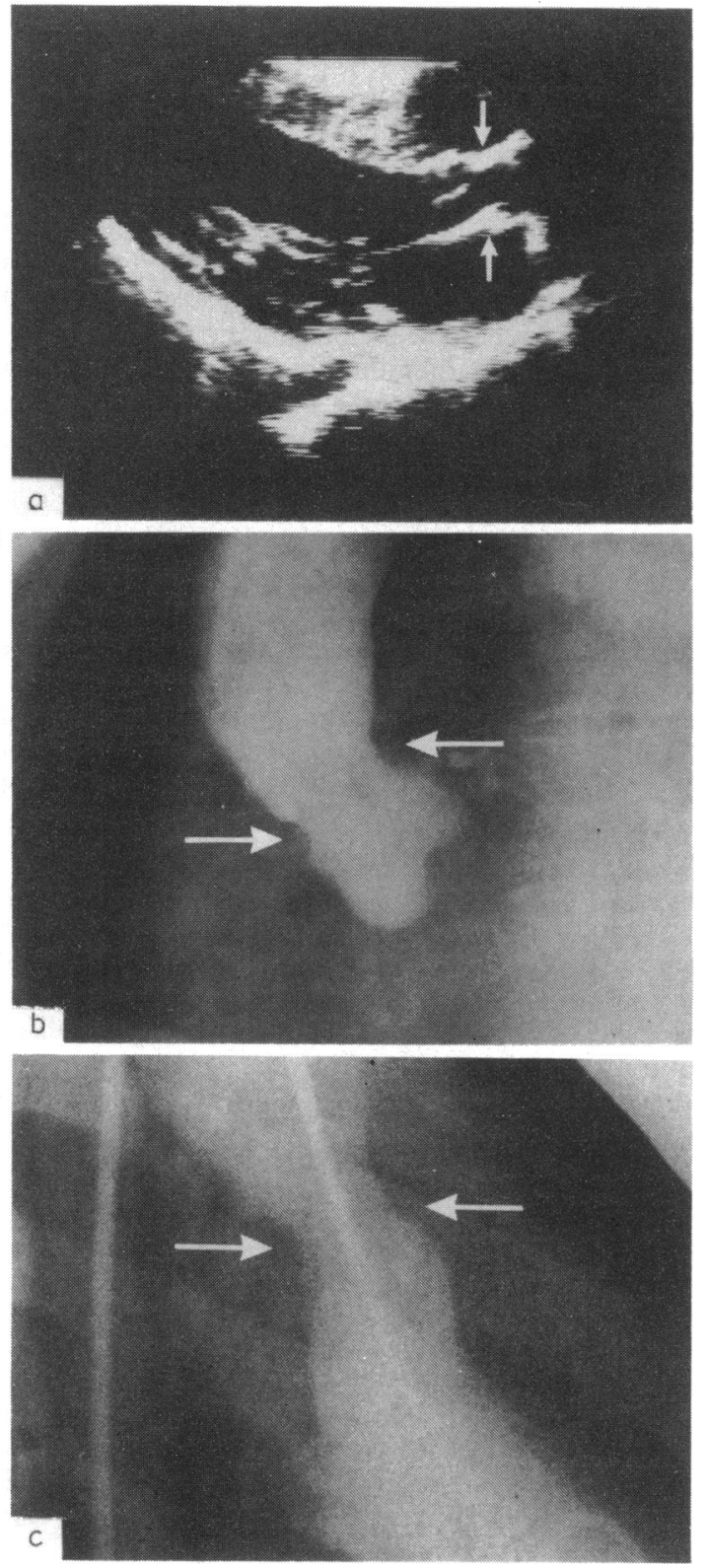

Fig. 1 Case 1 (homozygote). Parasternal long axis view (a) showing supravalvular aortic stenosis (arrows) and normal aortic cusps. Fig. $1 b$ and $c$ show supravalvular narrowing (arrows) on a lefi lateral aortogram and right anterior oblique lefi ventriculogram.

heterozygotes respectively. Four had abnormal bright echoes encircling the aortic root, three of whom had mild supravalvular narrowing similar to, but less severe than, that seen in case 1 . One heterozygote had a $22 \%$ reduction in the supravalvular aortic dimension
Ribeiro, Shapiro, Gonzalez, Thompson, Oakley
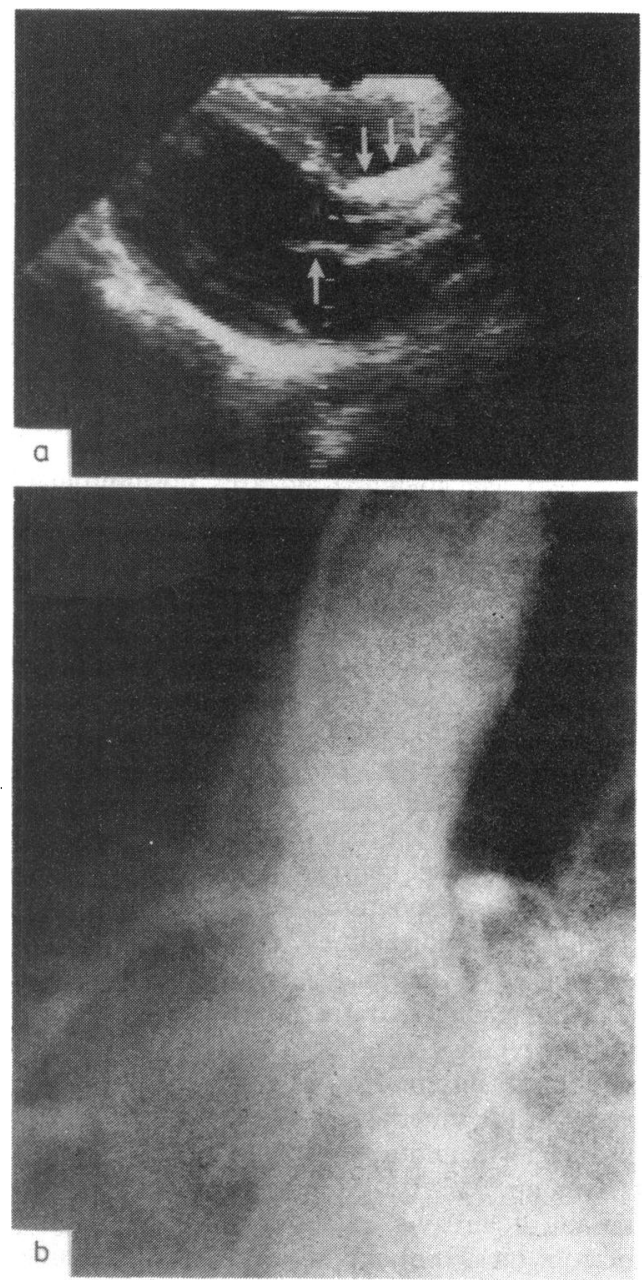

Fig. 2 Case 2 (homozygote). Parasternal long axis view (a) showing many abnormal bright echoes within the aortic root (atheroma) extending upwards from the aortic valve and interfering with aortic cusp excursion. Note generalised thickening of the anterior leaflet of the mitral valve (arrows). (b) Aortogram (left lateral projection) showing the characteristic aortic root funnelling.

(Table). All three aortic valve cusps were thickened, but their opening was restricted by the supravalvular narrowing (Fig. 4); this was confirmed at coronary artery bypass surgery, when a $15 \mathrm{~mm}$ valvular gradient was also found.

\section{Discussion}

Previous angiographic studies have shown characteristic aortic root funnelling, which is often associated with aortic valvular gradients, in patients with homozygous familial hypercholesterolaemia. 5 We 


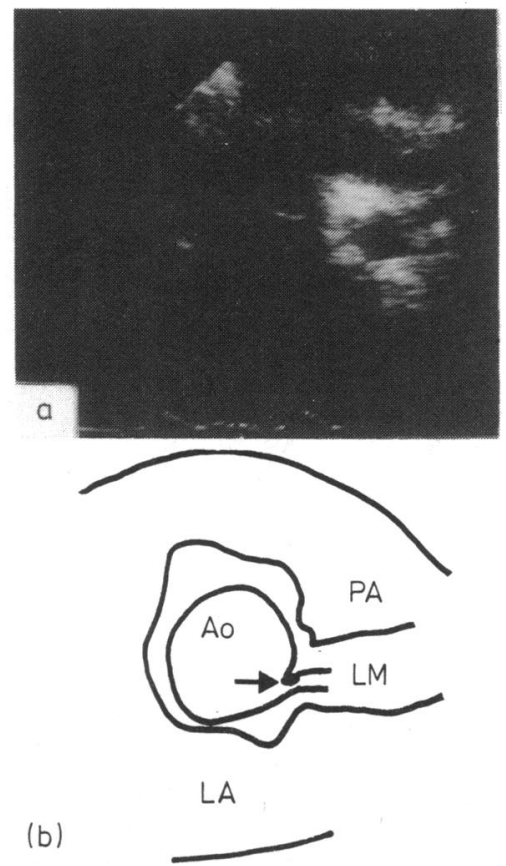

Fig. 3 Case 3 (homozygote). Echocardiogram (a) with diagrammatic representation (b) of a short axis parasternal view showing lefi coronary ostial stenosis (arrows). PA, pulmonary artery; $L A$, left atrium; $A o$, ascending aorta; $L M$, left main coronary artery.

have shown that echocardiography and angiography give comparable results and that a wide spectrum of abnormalities may be seen. Abnormal bright echoes arising from the aortic root and valve were often noted, and in two homozygotes and one heterozygote supravalvular atheroma prevented full aortic valve opening and was responsible for the valvular gradients. Supravalvular narrowing was clearly seen in one homozygote by cross sectional echocardiography and confirmed by the presence of a supravalvular pressure gradient. Only one previous case of pronounced supravalvular aortic stenosis has been described in a homozygote. ${ }^{9} \mathrm{~A}$ considerable reduction in aortic lumen has to be present before a gradient develops, and premature coronary artery disease dominates the clinical picture. ${ }^{2910}$ In two of our homozygotes the mechanism of valvular stenosis was secondary to supravalvular atheroma preventing normal cusp motion. Classic hourglass supravalvular aortic stenosis with echocardiographically normal cusps was also shown. In addition, one homozygote showed generalised mitral valve thickening. This can lead to haemodynamically important stenosis if calcification occurs. ${ }^{1112}$
Cross sectional echocardiography offers an opportunity to study less severely affected patients in whom invasive investigations may not be justified. Of 32 heterozygotes 22 were normal, but 10 had abnormal echoes arising from the aortic valve or root. In three heterozygotes supravalvular changes similar to those in homozygotes were noted, and one had aortic valvular stenosis. This patient also had abnormal bright echoes within the sinus of Valsalva, which were associated with limitation of full excursion of the cusps. While coronary and peripheral artery stenosis may be found in both homozygotes and heterozygotes, aortic valve lesions were believed to be unique to the former. ${ }^{6}$ We have shown, however, that heterozygotes may have aortic valve abnormalities, root thickening, and narrowing in a similar (but usually less severe) manner to homozygotes. This is not surprising as it is possible that the serum cholesterol concentration determines the rate of deposition of lipid and overlap may occur between heterozgotes and homozygotes.

Aortic valve and root lesions consist of foam cells, cholesterol crystals, and fibrocalcific deposits. ${ }^{2}$ The intracellular lipid and cholesterol crystals within the aortic cusps differentiate these lesions from other causes of aortic valve disease. Similar lesions may be induced experimentally in rats fed on a high cholesterol diet. ${ }^{13}$ The mechanism of atheroma formation is probably an increased influx of low density lipoprotein in areas of high sheer stress, such as the sinotubular junction and aortic and mitral valves. ${ }^{14}$ The tricuspid and pulmonary valve are not affected, perhaps because they are not submitted to such great sheer stress.

Cholesterol concentrations in homozygotes may vary widely depending on the available number of cellular receptors. ${ }^{15}$ These range from 0 to $10 \%$ of the normal number of low density lipoprotein receptors, ${ }^{16}$ which probably explains the wide age range of morbidity and mortality in homozygous familial hypercholesterolaemia. Myocardial infarction can occur as early as 18 months of age, but survival beyond the age of 30 has also been reported. Most homozygotes, however, die before the age of 25.17

The left main coronary artery may be identified by cross sectional echocardiography, and stenosis has been shown in some patients. ${ }^{18}$ Our homozygote patients were young, but we found left coronary ostial stenosis in all three; right coronary ostial stenosis was not recognised in one homozygote, however, in whom it was shown by coronary angiography.

In conclusion, cross sectional echocardiography may show valvular or supravalvular obstruction and coronary ostial stenosis in patients with homozygous familial hypercholesterolaemia. In addition, heterozygotes may show similar aortic root and valve 

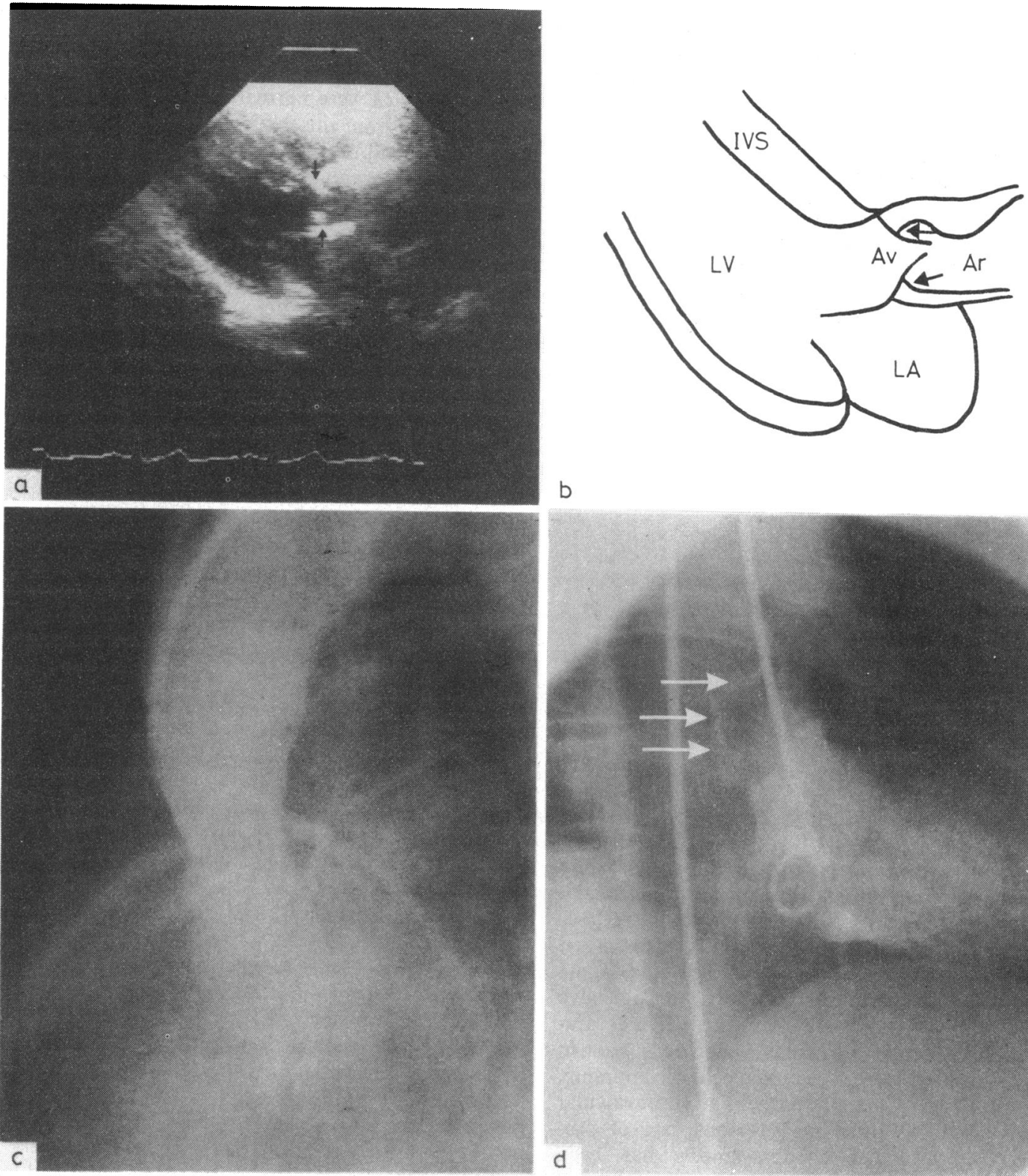

b

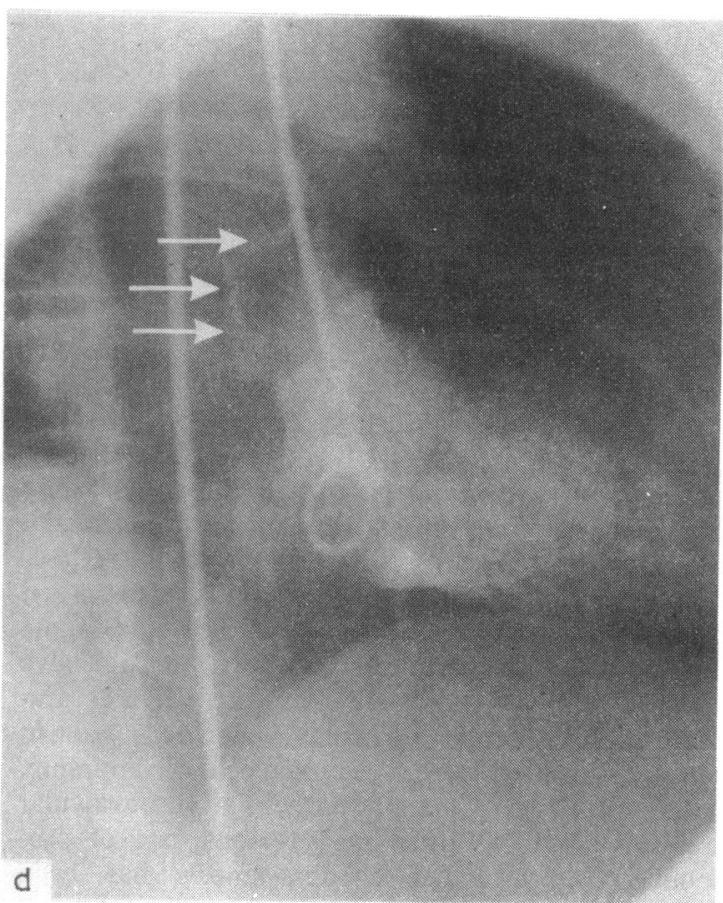

Fig. 4 Case 4 (heterozygote). Echocardiogram (a) with diagrammatic representation (b) of a parasternal long axis view showing an abnormal bright mass of echoes (atheroma) within the sinus of Valsalva interfering with aortic cusp excursion (arrows). Note the abnormal thickened basal portion of the aortic valve. Aortogram (c) (left lateral projection) showing aortic root funnelling, similar to the homozygote. Supravalvular aortic calcified atheroma (arrows) (d) on a right anterior oblique left ventriculogram. Ar, aortic root; $A v$, aortic valve; $L V$, left ventricle; IVS, interventricular septum; $L A$, left atrium.

abnormalities, although these are usually less severe. Serial cross sectional echocardiographic studies may well prove useful for monitoring the progress of the disease and the effect of treatment such as plasma exchange.

\section{References}

1 Roberts WC. The status of the coronary arteries in fatal ischemic heart disease. Cardiovasc Clin 1975; 7: 1-24.

2 Roberts WC, Ferrans VS, Levy RI, Fredrickson DS. 
Cardiovascular pathology in hyperlipoproteinemia. $A m \mathcal{F}$ Cardiol 1973; 31: 557-70.

3 Barr DP, Rothbard S, Eder HA. Atherosclerosis and aortic stenosis in hypercholesterolemic xanthomastosis. FAMA 1954; 156: 943-7.

4 Stanley P, Chartrand C, Davignon A. Acquired aortic stenosis in a 12 year old girl with xanthomatosis. $N$ Engl f Med 1965; 273: 1378-80.

5 Allen JM, Thompson GR, Myant NB, Steiner R, Oakley CM. Cardiovascular complications of homozygous familial hypercholesterolaemia. Br Heart f 1980; 44: 361-8.

6 Fredrickson DS, Levy RI. Familial hyperlipoproteinemia. In: Stanbury JB, Wyngaarden JB, Fredrickson DS, eds. The metabolic basis of inherited disease. New York: McGraw Hill, 1972: 545-614.

7 Heiberg A. The risk of atherosclerotic vascular disease in subjects with xanthomatosis. Acta Med Scand 1975; 198: 249-61.

8 Sahn DJ, DeMaria A, Kisslo J, Weyman A. The committee of M-mode standardization of the American Society of Echocardiography. Circulation 1978; 58: 1072-83.

9 Wennevold A, Jacobsen JG. Acquired supravalvular aortic stenosis in familial hypercholesterolemia. Am $\mathcal{J}$ Med 1971; 50: 823-7.

10 Weyman AE, Caldwell RL, Hurwitz RA, et al. Cross sectional echocardiographic characterization of aortic obstruction. I. Supravalvular aortic stenosis and aortic hypoplasia. Circulation 1978; 57: 491-7.

11 Zahor Z, Czabonova V. Experimental atherosclerosis of the heart valves in rats following long term atherogenic diet. Atherosclerosis 1977; 27: 49-57.
12 Maher JA, Epstein FH, Hand EA. Xanthomatosis and coronary heart disease: necropsy study of two affected siblings. Arch Intern Med 1958; 102: 437-42.

13 Schettler FG. Essential familial hypercholesterolaemia. In: Schettler FG, Boyd GS, eds. Atherosclerosis. Amsterdam: Elsevier, 1969: 543.

14 Fry DL. Responses of the arterial wall to certain physical factors. In: Ciba Foundation Symposium 12 (New Series). Atherogenesis: initiating factors. Amsterdam: Associated Scientific Publishers, 1973: 93-125.

15 Thompson GR. Familial hypercholesterolaemia. In: Peeters H, ed. The lipoprotein molecule. (Nato Advanced Study Institute Series. Series A: Life Sciences, Vol. 15.) New York: Plenum Press, 1978: 215-26.

16 Goldstein JL, Dana SE, Brunschede GY, Brown MS. Genetic heterogeneity in familial hypercholesterolemia: evidence for two different mutations affecting functions of low density lipoprotein receptor. Proc Natl Acad Sci USA 1975; 72: 1092-6.

17 Cook CD, Smith HL, Giesen CW, Berdez GL. Xanthoma tuberosum, aortic stenosis, coronary sclerosis and angina pectoris. Am $\mathcal{F}$ Dis Child 1947; 73: 326-33.

18 Weyman AE, Feigenbaum H, Dillon JC, Johnson KW, Eggleton RC. Noninvasive visualization of the left main coronary artery by cross sectional echocardiography. Circulation 1976; 54:169-74.

Requests for reprints to Dr Celia M Oakley, Royal Postgraduate Medical School, London W12 0HS. 